\title{
Prospective study of ultrasonography in chronic pancreatic disease
}

\author{
W R LEES, A G VALLON, M E DENYER, S P VAHL, P B COTTON
}

\section{Patients and methods}

Two hundred and eighteen consecutive and unselected patients being investigated for known or suspected pancreatic disease entered the study. We eventually excluded six patients from the final analysis, since a firm and final diagnosis could not be established. The first 92 patients were studied retrospectively to define the ultrasonographic features of the normal and diseased pancreas. These criteria (see below) were then applied prospectively to the next 120 patients to determine the accuracy of the technique and its clinical contribution.

Ultrasonographic technique-The patients were scanned by a single operator (WRL) using a modified Nuclear Enterprises Diasonograph NE 4102, with NE 4104 grey-scale facility. A range of transducers was used, the most useful being a long internal-focus $2.5 \mathrm{mHz}$ transducer. The major modification to the Diasonograph was the addition of a large formal oscilloscope (Lan) with a long-persistence phosphor, which provided a good grey-scale and allowed a rapid scanning technique to be adopted. Patients were asked to fast for about four hours before the procedure; no bowel preparation was given. Scans were performed with patients in the supine and left lateral decubitus positions; the transducer was applied in the sagittal and horizontal planes, with varying degrees of obliquity.

Ultrasonographic criteria-The pancreas was identified by anatomical markers and by its characteristic internal appearance. Consistent diagnostic criteria were derived from the appearances of the parenchyma and the duct system, from the size and shape of the gland, and from previous reports. ${ }^{7-10}$ The main diagnostic problems were caused by poor visualisation through excessive intestinal gas or obesity. In the 92 patients studied retrospectively the most common features seen in chronic pancreatitis (22 patients) were increased reflectivity of the parenchyma (20), irregularity of the organ boundary (10), disorganisation of the normal duct pattern (9), and local or general enlargement (6). Of 11 patients known to have recurrent attacks of acute pancreatitis, only three showed the ultrasound features classically seen in acute pancreatitis-that is, general enlargement of the gland, loss of duct pattern, low reflectivity of the parenchyma, and per-pancreatic effusions. Three patients had the ultrasound features of chronic pancreatitis, and one showed changes of both chronic and acute pancreatitis. In four patients the scans were entirely normal. The ultrasound features of pancreatic cancer were as described. ${ }^{9-11}$ The features are dependent on tumour size: small tumours are homogeneous, poorly reflective masses with irregular borders, while large tumours tend to be non-homogeneous, strongly reflective masses with irregular borders.

Methods of prospective assessment (clinical and ultrasonographic) The prospective study of 120 patients was devised to test the efficiency of ultrasonography, and its contribution over and above the purely clinical assessment, in answering the following three questions. (1) Is the pancreas normal or abnormal? (2) If abnormal, is the disease cancer or pancreatitis? (3) If pancreatitis, is there a localised lesion? We studied 98 patients as problems in diagnosis, and all three questions were relevant. Only question 3 was relevant to the remaining 22 patients, who were known to have recurrent or chronic pancreatitis. All patients were first assessed by a clinician who attempted to answer the questions on the basis of all available evidence (case history, examination, biochemistry, and previous radiology); he graded his conclusions as definite (3), probable (2), or doubtful (1). Ultrasonography was then performed and reported with access to the clinical assessment; reports were also given a confidence grade $(1,2$, or 3). Some measure of the value of ultrasonography is given by comparing the clinical and scan assessments and their relative scores.

Final diagnosis-The final conclusion concerning the state of the pancreas was established at the end of the study by considering all available data, excluding the results of ultrasonography. Table I indicates the main criteria used in the $\mathbf{9 8}$ patients studied as problems in diagnosis. Of the total group of 120 patients studied prospectively, 100 underwent endoscopic retrograde cholangiopancreatography (ERCP), and 46 laparotomy. Detailed pancreatic function tests were performed in nine doubtful cases. Sixty-five patients were finally
W R LEES, MB, BS, registrar, department of clinical measurement A G VALLON, MB, MRCP, medical registrar

M E DENYER, MB, MRCP, research assistant (present address: The Whittington Hospital, London N19)

S P VAHL, MB, MRCOG, senior registrar, department of clinical measurement P B COTTON, MD, FRCP, consultant physician 
diagnosed as not having pancreatic disease; in 48 of these a convincing alternative diagnosis was provided. In the remaining 17 a normal pancreas was confirmed clinically on the basis of negative test results (ERCP showed nothing abnormal in all cases) and satisfactory followup of at least six months.

TABLE I-Final diagnoses in 98 patients studied as problems in diagnosis, with results of main additional diagnostic methods

\begin{tabular}{|c|c|c|c|}
\hline \multirow[t]{2}{*}{ Final diagnosis } & \multirow[t]{2}{*}{ Total } & \multicolumn{2}{|c|}{$\begin{array}{l}\text { Main additional diagnostic } \\
\text { methods }\end{array}$} \\
\hline & & ERCP & Laparotomy \\
\hline $\begin{array}{ccc}\text { Pancreas normal } & . & \ldots \\
\text { No other disease } & . & \ldots \\
\text { Biliary disease } & \cdots & \\
\text { Other gastrointestinal disease }\end{array}$ & $\begin{array}{l}17 \\
30 \\
18\end{array}$ & 51 & 20 \\
\hline $\begin{array}{l}\text { Cancer (pancreatic or papillary) } \\
\text { Chronic pancreatitis (cysts) }\end{array}$ & $20(4)$ & $\begin{array}{l}10 \\
20\end{array}$ & $\begin{array}{r}12 \\
4\end{array}$ \\
\hline Totals & 98 & 81 & 36 \\
\hline
\end{tabular}

ERCP $=$ Endoscopic retrograde cholangiopancreatography.

\section{Results}

Ultrasonography failed to provide diagnostic information in three cases, due to excessive intestinal gas.

Question 1: Is the pancreas normal or abnormal? Ultrasonography detected all 33 abnormal glands, with no false-normal reports (table II). Among the 65 patients with a normal pancreas, four had false-positive ultrasound reports (two cancer, two chronic pancreatitis). The overall accuracy of the ultrasonographic diagnosis $(94 \%)$ greatly exceeded that of the clinical assessment alone $(63 \%)$. Table III compares their accuracies and confidence scores. Ultrasound and clinical diagnoses were both correct in 59 cases and both wrong in two cases. Ultrasound was correct and the clinical assessment false in 33 cases, and ultrasound false and the clinical diagnosis correct in only two. The ultrasound report was graded as definite (3/3) for 67 out of the 96 successful scans; all 67 were correct. Twenty-four out of the 28 graded as probable $(2 / 3)$ were also correct. The clinical assessment was graded as definite in only 39 cases, and was correct in 32 . Fifty of the clinical reports were graded as probable, and only 26 proved to be correct. Overall, ultrasonography gave a more accurate or a more confident and accurate diagnosis than the clinical assessment in 57 of the 98

TABLE II-Overall diagnostic accuracy of clinical and ultrasonographic diagnoses

\begin{tabular}{|c|c|c|c|c|c|c|}
\hline \multirow{2}{*}{\multicolumn{2}{|c|}{ Diagnosis }} & \multicolumn{2}{|c|}{ Correct } & \multicolumn{2}{|c|}{ False } & \multirow{2}{*}{$\begin{array}{c}\text { Overall } \\
\text { accuracy } \\
(\%)\end{array}$} \\
\hline & & Normal & Abnormal & Normal & Abnormal & \\
\hline $\begin{array}{l}\text { Final .. } \quad . \\
\text { Clinical } \\
\text { Ultrasonographic }\end{array}$ & $\begin{array}{l}. \\
.\end{array}$ & $\begin{array}{l}65 \\
41 \\
61\end{array}$ & $\begin{array}{l}33 \\
21 \\
33\end{array}$ & 12 & $\begin{array}{r}24 \\
4\end{array}$ & $\begin{array}{l}63 \\
94\end{array}$ \\
\hline
\end{tabular}

TABLE III-Accuracy and confidence of ultrasound and clinical diagnoses with regard to question 1: Is pancreas normal or abnormal? (Two cases in which ultrasound failed are excluded)

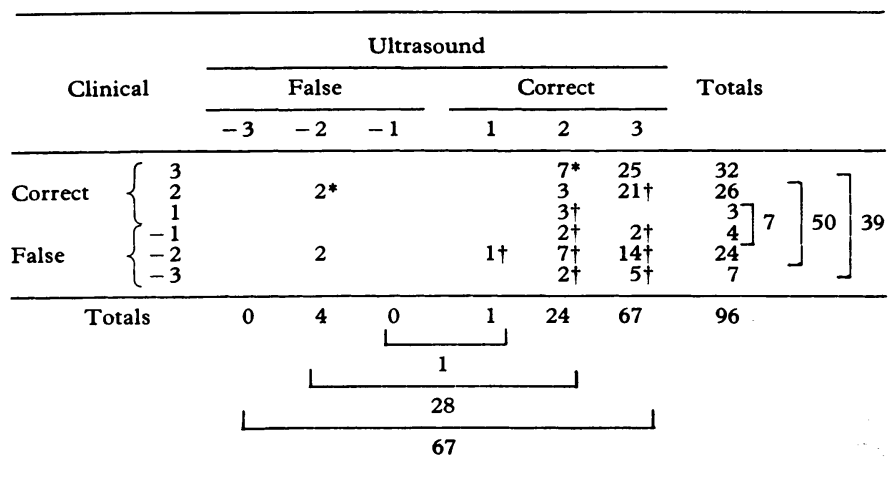

*Patients in whom clinical diagnosis more accurate than ultrasound assessment. tPatients in whom ultrasound diagnosis gave more accurate or more confidently patients studied. The clinical assessment was more accurate than ultrasonography in only two cases, and was more confident when both assessments were correct in a further seven.

Question 2: If abnormal, is the disease cancer or pancreatitis ? Thirtythree of the 98 patients studied as problems in diagnosis were subsequently shown to have chronic pancreatic disease. Ultrasonography not only detected pancreatic abnormality (tables II and III) but also accurately distinguished cancer from pancreatitis in all cases (table IV), all 13 patients with cancer and 20 with chronic pancreatitis being correctly diagnosed. Two-thirds of the ultrasound reports were graded as definite (table IV). The accuracy of clinical diagnosis in distinguishing between cancer and chronic pancreatitis was only $75 \%$.

Question 3: If pancreatitis is present, is there a localised lesion?-In this context we assessed only the presence or absence of a mass or pseudocyst. Forty-two patients had chronic pancreatitis (including those already known to have pancreatic disease). Four subsequently had pseudocysts confirmed at surgery. Ultrasonography detected all four of these lesions, but one was interpreted as a mass ?tumour; there were no false-positive reports.

TABLE IV-Confidence of diagnoses in which ultrasound correctly distinguished cancer from pancreatitis

\begin{tabular}{|c|c|c|c|c|c|}
\hline \multirow{2}{*}{\multicolumn{2}{|c|}{ Final diagnosis }} & \multicolumn{3}{|c|}{ Confidence } & \multirow{2}{*}{ Total } \\
\hline & & 1 & 2 & 3 & \\
\hline $\begin{array}{l}\text { Cancer } \\
\text { Pancreatitis }\end{array}$ & $\because$. & & $\begin{array}{l}5 \\
6\end{array}$ & $\begin{array}{r}8 \\
14\end{array}$ & $\begin{array}{l}13 \\
20\end{array}$ \\
\hline
\end{tabular}

\section{Discussion}

Clinicians favour tests that are acceptable to their patients, reliable, and relatively cheap, which means they are likely to be available. A useful test must have a low failure rate, a low rate of false-positive diagnoses in normal subjects, and a low rate of false-normal reports in those with disease. In this study ultrasonography fulfilled these criteria remarkably well, and results compared favourably with those reported from other centres (table V). Clinicians rapidly lose confidence in diagnostic tests whose false-negative or false-positive rates exceed $10 \%$. Since this has occurred in some series whose results have been published it is important to consider the reasons why results may differ.

TABLE V-Published results of ultrasonography

\begin{tabular}{|c|c|c|c|c|}
\hline$\cdots$ & & $\begin{array}{l}\text { No }(\%) \text { of } \\
\text { failures }\end{array}$ & $\begin{array}{l}\text { No }(\%) \text { of } \\
\text { false-negative } \\
\text { results in cancer } \\
\text { or pancreatitis }\end{array}$ & $\begin{array}{c}\text { No }(\%) \text { of } \\
\text { false-positive } \\
\text { results in } \\
\text { normal cases }\end{array}$ \\
\hline 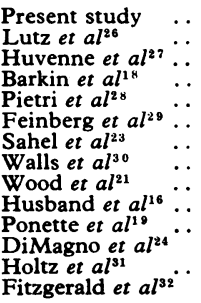 & $\begin{array}{l}\because \\
\because \\
\cdots \\
\cdots \\
\cdots \\
\because \\
\because \\
\because \\
\cdots \\
\cdots\end{array}$ & $\begin{array}{l}10 / 50(20) \\
12 / 133(9)\end{array}$ & $\begin{array}{l}0 / 33(0) \\
3 / 84(4) \\
2 / 38(5) \\
2 / 33(6) \\
4 / 59(7) \\
2 / 25(8) \\
8 / 72(11) \\
8 / 53(15) \\
6 / 36(17) \\
3 / 16(19) \\
5 / 24(21) \\
9 / 34(26) \\
10 / 35(29) \\
9 / 27(33)\end{array}$ & $\begin{array}{l}4 / 65(6) \\
6 / 63(10) \\
5 / 35(14) \\
0 / 13(0) \\
0 / 7(0) \\
8 / 41(20) \\
7 / 33(21) \\
\\
2 / 14(14) \\
1 / 21(5) \\
5 / 30(17) \\
18 / 78(23) \\
5 / 18(28)\end{array}$ \\
\hline
\end{tabular}

The difficulties encountered with pancreatic ultrasonography are primarily those of obtaining adequate visualisation of the gland against a background of gastrointestinal gas, which forms an absolute barrier to the passage of ultrasound, but views are also compromised by excessive fat and fibrous tissue (as after abdominal surgery). Diagnostic statements can be made only when the gland has been identified anatomically and unequivocally in relation to other anatomical structures, and when the interrogating beam has traversed structures with known acoustic properties, such as the liver and kidney. ${ }^{12}$ Diagnostic 
accuracy depends on maintaining the ultrasound equipment in optimal condition, paying great attention to anatomical detail, and considerable experience. Experience is required both in obtaining appropriate scans (by active "interrogation" of the patient) and in interpreting the images. The relative importance of these different aspects of experience and the difficulties in teaching them have not yet been established.

This study has shown that grey-scale ultrasonography has important diagnostic and management roles in patients with chronic pancreatic disease, as has been established in patients with acute pancreatitis and evolving pseudocysts. ${ }^{13} 14$

Where do these results leave other diagnostic techniques? Pancreatic function tests are occasionally important, but imaging methods are more discriminating. Pancreatic isotope scanning has been discarded in this unit, ${ }^{1}$ and angiography is used only in highly selected cases. Computerised axial tomography provides good images of the pancreatic outline ${ }^{15}$ and is preferable to ultrasonography in obese patients, in whom ultrasound is particularly difficult, ${ }^{16}$ but preliminary comparisons have shown no other convincing advantage over ultrasonography. ${ }^{17-19}$ We find that ultrasonography gives better overall diagnostic discrimination; in our unit computerised tomography of the pancreas is reserved for a few problem patients, often those with mass lesions who have undergone surgery.

Ultrasonographic diagnosis is based on the appearance of the organ outline and its parenchyma. It is therefore well complemented by invasive techniques that outline the duct system, such as $E R C P^{20}$ and percutaneous transhepatic cholangiography in patients with jaundice. Like others who have studied this topic, ${ }^{21-24}$ we now recommend the combination of grey-scale ultrasonography and ERCP. ${ }^{25}$ The ultrasonography is performed first, and this diagnosis may be sufficient if it is confidently normal in a patient in whom the clinical suspicion of pancreatic disease is low. In most other cases ultrasonography is followed by ERCP to complete the documentation and give information about the duodenal loop and papilla of Vater.

Ultrasound technology is advancing rapidly, and high-resolution "real-time" (moving-picture) systems will soon be in general use. Images of diagnostic quality are becoming easier to achieve, and developments should decrease the degree of operator dependence. These advances should consolidate the position of pancreatic ultrasonography and allow the technique to be widely adopted as an easy and early diagnostic method in the study of pancreatic problems.

\section{References}

${ }^{1}$ Cotton, P B, et al, British Medical fournal, 1978, 1, 282.

${ }^{2}$ Howry, D H, Radiologic Clinics of North America, 1965, 3, 433.

${ }^{3}$ Lancet, 1977, 2, 1212.

4 Woodward, B, Pond, J B, and Warwick, R, British fournal of Radiology, $1970,43,719$.

${ }^{5}$ Baker, M L, and Dalrymple, G V, Radiology, 1978, 126, 479.

6 Vallon, A G, Lees, W R, and Cotton, P B, Gut. In press.

7 Doust, B D, and Pearce, J D, Radiology, 1976, 120, 653.

${ }^{8}$ Haber, K, Freimanis, A K, and Asher, W M, American fournal of Roentgenology, 1976, 126, 624.

${ }^{9}$ Leopold, G R, Fournal of the American Medical Association, 1975, $232,287$.

10 Taylor, K J W, and Rosenfield, A T, Clinics in Gastroenterology, 1978, 7, 488.

${ }^{11}$ Ferrucci, J T, Radiologic Clinics of North America, 1976, 15, 543.

12 Freimanis, A K, and Asher, W M, American fournal of Roentgenology, 1970, 198, 747.

13 Duncan, J C, Imrie, C W, and Blumgart, L H, British fournal of Radiology, 1976, 49, 858 .

14 Weill, F, et al, Archives Françaises des Maladies de l'Appareil Digestif, 1976, 65, 443.

${ }^{15}$ Fawcitt, R A, Forbes, W St C, and Isherwood, I, British fournal of Radiology, 1978, 51, 1 .

${ }^{16}$ Husband, J E, Meire, H B, and Kreel, L, British fournal of Radiology, $1977,50,855$.

17 Cotton, P B, et al, Gut, 1978, 19, 679.

${ }^{18}$ Barkin, J, et al, fournal of the American Medical Association, 1977, 238, 2040.

${ }^{19}$ Ponette, E, et al, Acta Gastro-enterologica Belgica, 1976, 34, 402.

${ }^{20}$ Cotton, P B, Gut, 1977, 18, 316.

${ }^{21}$ Wood, R A B, et al, Surgery, 1976, 80, 518.

${ }^{22}$ Freeny, P C, and Ball, T J, Radiology, 1978, 127, 627

${ }^{23}$ Sahel, J, et al, Acta Endoscopica et Radiocinematographica, 1976, 6, 7.

${ }^{24}$ DiMagno, E P, et al, New England fournal of Medicine, 1977, 297, 727.

${ }^{25}$ Cotton, $\mathrm{P}$ B, et al, Radiology. In press.

${ }^{26}$ Lutz, H, et al, Klinische Wochenschrift, 1975, 53, 419.

27 Huvenne, R, et al, Acta Gastro-enterologica Belgica, 1976, 34, 475.

${ }^{28}$ Pietri, H, et al, La Nouvelle Presse Médicale, 1977, 42, 3833.

${ }^{29}$ Feinberg, S B, Schreiber, D R, and Goodale, R, Fournal of Clinical Ultrasound, 1977, 5, 96.

${ }^{30}$ Walls, W J, et al, Radiology, 1975, 114, 127.

${ }^{31}$ Holtz, V U, Falck, J, and Frankin, F H, Zeitschrift für Gastroenterologie, $1977,15,600$.

${ }^{32}$ Fitzgerald, P J, et al, Cancer, 1978, 41, 868.

(Accepted 31 October 1978)

\section{SHORT REPORTS}

\section{Delayed haemorrhagic disease of the newborn with extradural haematoma}

In breast-fed newborn infants there is an increased risk of haemorrhagic disorders associated with vitamin $\mathrm{K}$ deficiency. ${ }^{1}$ Beyond the neonatal period the aetiological role of breast-feeding is less clear. In those cases where symptomatic vitamin $\mathrm{K}$ deficiency has occurred there have often been other predisposing factors such as previous antibiotic treatment or prolonged diarrhoea. ${ }^{2}{ }^{3}$ We describe a breastfed infant who had received no vitamin $\mathrm{K}$ after delivery and who developed a bleeding tendency at four weeks, later resulting in an extradural haematoma.

\section{Case report}

A 6-week-old baby girl presented with a two-week history of bruising and bleeding from the palate. Her mother was a 38-year-old Greek Cypriot, gravida three, with thalassaemia minor. She was induced at 37 weeks gestation for mild hypertension. Delivery was normal, and the birth weight $2 \cdot 2 \mathrm{~kg}$. The baby was not given vitamin $\mathrm{K}$ after delivery. Apart from mild transitory jaundice, the neonatal period was uneventful. She had been entirely breast-fed up to the time of presentation. There was no history of antibiotic treatment or episodes of diarrhoea. She was a pale baby, with bruising of her left hand and right side of her face. Apart from an umbilical hernia, there were no other positive findings. Investigations gave the following results: haemoglobin concentration $4.9 \mathrm{~g} / \mathrm{dl}$, reticulocytes $16 \%$, WBC $9 \times 10^{9} / 1\left(9000 / \mathrm{mm}^{3}\right)$, normal platelets, prothrombin time $>5$ minutes, kaolin cephalin clotting time $>5$ minutes, and normal liver function tests. Clotting factor assays were performed: II $<1 \%$, V $>150 \%$, IX $<3 \%$, $\mathrm{X}<1 \%$. These results confirmed a diagnosis of vitamin $\mathrm{K}$ deficiency leading to haemorrhagic disease. She was treated with fresh frozen plasma, whole blood, and vitamin $\mathrm{K}$. Repeat $\mathrm{Hb}$ was $13.9 \mathrm{~g} / \mathrm{dl}$ and the clotting screen 24 hours later was normal.

Over the next $\mathbf{4 8}$ hours she became febrile and irritable. A bacteriological screen, including lumbar puncture, was negative. Within a further 24 hours she had developed acute neurological symptoms-bulging fontanelle, widening of the sutures, conjugate deviation of her eyes to the left, and, finally, generalised seizures. A repeat lumbar puncture obtained uniformly blood-stained fluid, but bilateral subdural taps were negative. An electroencephalogram showed greatly reduced activity on the left side. Computerised axial tomography (CAT scan) four days after admission showed a large left occipital extradural haematoma (figure a). This was drained surgically and she made an uneventful postoperative recovery. She had no further seizures and her clotting screen remained normal. She has been followed up at regular intervals. At the age of 5 months her general level of development appeared normal. It was possible, however, to demonstrate a right homonymous hemianopia and difficulty in conjugate deviation of her eyes to the right. Spontaneous movement was reduced in the right arm and leg. A repeat CAT scan (figure b) showed atrophy in the posterior half of the left hemisphere. 